\title{
Applicability of IoT in Solid Garbage Collection and Monitoring System for Smart Cities
}

Dominic Abuga ( $\nabla$ abugah.dominic@gmail.com )

Delhi Technological University

\section{Nallanthighal Raghava}

Delhi Technological University

\section{Research Article}

Keywords: IoT, GSM modem, Raspberry Pi, Ultrasonic sensor

Posted Date: March 29th, 2021

DOl: https://doi.org/10.21203/rs.3.rs-352350/v1

License: (c) (1) This work is licensed under a Creative Commons Attribution 4.0 International License. Read Full License 


\section{Abstract}

Waste management has been a challenge to many cities globally. Improper disposal of waste is harmful to human beings, flora, and fauna. In human beings, inappropriate waste disposal results in waterborne diseases such as typhoid and cholera, which are very dangerous. Waste collected and dumped in landfills produces methane gas which is more dangerous than carbon dioxide. Methane is a greenhouse gas, causes global warming, which has severe ramifications for our planet. In this paper, the applicability of loT in solid garbage collection and monitoring framework for smart cities has been put forward. The proposed system is built using a Raspberry Pi Uno board that is interfaced with a weight sensor, ultrasonic sensor, and a GSM modem. The weight sensor will be placed at the bottom of the garbage bin for weight measurement. The Ultrasonic sensor will be affixed at the top of the garbage bin in order to measure the levels of waste. The Raspberry will have to be programmed in such a manner that when the garbage is almost being filled up, the other remaining level/height from the threshold level will be automatically displayed. When the solid waste in the garbage bin reaches the threshold weight, it will also set off the GSM modem, which will notify the person in charge of garbage collection. The personnel will send a message to the administrator in charge of garbage collection vehicles.

\section{Introduction}

The growth of the internet in the $21^{\text {st }}$ century has resulted in the emergence of a new technology called internet of things. loT allows all physical devices such as sensors, actuators, and other intelligent nodes to communicate with one another from anywhere at any time. loT is preferably the backbone of future trends in communication systems. It is projected that everything will be able to share information and communicate smartly with one another without any human interference. All the physical devices will have the computational capacity that will enable them to monitor the external environment that will enhance smart cities' development and growth. loT technology has been applied in so many fields: health, traffic monitoring, agriculture, fleet management, hospitality, smart grid, and waste management.

According to the World Bank report of 2019 , cities generate almost $40 \%$ of the world's waste, and the waste generated globally will increase from 2 billion tonnes to 3.5 billion tonnes by the year 2050 . Waste management and control have been a challenge to urban planners and engineers over a long time. Waste collection and monitoring are quite expensive for city municipalities when technology is not incorporated. In the system proposed, two sensors will be used: the ultrasonic sensor and the weight sensor with a combination of Raspberry Pi micro-controller and a GSM communication module. The system guarantees timely emptying of garbage bins when the waste exceeds a certain threshold level and weight. If the garbage bin has attained a certain threshold in weight and level and is not emptied, then a message is generated sent to authorities who will take action on the concerned garbage collector. Through this message's generation, the system ensures that the collection and management of waste in smart cities is efficient. The system also reduces the cost of fuel in the collecting vehicles because responses are required once a garbage bin achieves a certain threshold. 
In the new loT trends, global loT infrastructures provide us a mechanism of collecting data and using the same data to tackle problems facing the smart cities. Nowadays, the garbage collection vehicles pick garbage bins whether they are full or not. In our system, genetic algorithms (GA) will be used in optimizing garbage collection. The genetic algorithms will be used to help the garbage collection vehicles more efficiently in crowded places such as residential and industrial areas. In this paper, experimental scenarios of GA application in the loT environment will also be highlighted. For a cleaner and hygienic environment that will be safe for residents of smart cities, the system proposed supersedes other existing systems in terms of cost and implementation.

\section{Literature Review}

According to [1], the authors focused on level, weight, capacity, pressure, humidity, and temperature sensors for solid waste collection and management. The authors went ahead to propose a garbage collection container that has sensors affixed to it. The sensor play a role in collection optimization and content estimation. The paper presented the design, development and implementation of an appropriate solid waste management system that has the ability to predict the diversity and quantity of the solid waste.

According to [2], the authors proposed a solid waste collection mechanism where the information was collected using RFID technology, and the information was then transmitted via a wireless mesh network. The proposed had shortcomings in long-distance considering that smart city applications should cover a large area. Also, the optimization algorithms' results became vague and could not apply to a smart city's real-time systems.

According to [3] the authors have adopted chemical, capacity, humidity, temperature, and weight sensors in solid waste collection. The authors of this paper then proposed a municipality solid waste collection and management that exploits recycling the collected information based on loT technology. A model for solid waste accumulation, collection, transportation, and recycling is displayed. The system is dependent on loT technology and has been used in solid waste gathering and collection models in Wuhan city in China. The system's results will help public health officials and municipal authorities use every information produced at every level of solid waste collection and eventually form an intelligent waste management cycle.

According to [4], smart city information collection plays a crucial role in the implementation, analysis, and development of smart cities. The authors proposed a fundamental tool based on information communication and technology that will help the municipality of Indonesia cities monitor what is happening within the city's environs. The system proposed uses a single dashboard in monitoring and summarizing the happenings in the city. The system uses wireless sensor networks (WSN) to provide information on air pollution, land pollution, water pollution, and roads' traffic situation. The prototype of the smart city dashboard is currently being used in Bandung city in Indonesia. 
According to [5], the authors presented a solid waste management and control stage to be used by smart cities using long-range wide area network (LoRaWAN) radio third-generation technology and route optimization. Besides, an implementation that is based on the internet of things was setup, but the proposed system did not provide any clarification about optimization and communication for all garbage bins in the proposed system.

According to [6], the authors proposed a system for optimal routing for effective and efficient solid garbage transportation that incorporates Dijkstra algorithm and GIS for solving the problem of finding the shortest path. The system was able to reduce the distance travelled by almost $10 \%$ besides, cost of transportation and time spent on the road was significantly reduced.

According to [7], the authors suggested that smart cities are to be designed and developed to make them habitable to all people. Smart cities should be able to apply the 3R model of re-use, reduce, and recycle to make waste collection process environment friendly. The authors then proposed an loT enabled that will be designed to achieve dynamic garbage assortment and delivery to the recycling plants because initially, many existing systems developed used the static classical approach. The system proposed is evaluated using real and artificial information from the municipality of Saint Petersburg in Russia. The system demonstrated accuracy and consistency.

According to [8], the authors have proposed a waste management and control system that ensures smart cities are clean. The system uses loT devices such as weight sensors, Ultrasonic sensors, and RFID tags to measure the city residents' interaction with garbage bins. Each garbage bin is equipped with the following; RFID reader, ultrasonic sensor, solar cell, weight sensor, and two LEDs, which will act as indicators when the garbage bin exceeds the threshold in weight and level one of the LEDs blinks red. Every city resident who wants to interact with this system must be provided with a card. However, this system's architecture is not efficient in terms of message dissemination, resource conservation, and garbage bin management.

According to [9], the authors proposed a system of applicability of wireless sensor networks (WSN) in solid waste management. WSN is a vital component in loT technology that has been widely used in traffic and waste management for smart cities. The proposed design takes into consideration the location of garbage bins that have been filled up and enhancing their transportation to the recycling plants/dumping sites. A decision support system (DSS) is readily available to provide solutions to resource organization challenges.

According to [10], the authors have proposed a system based on loT that aims to improve smart city infrastructure. The system has an in-depth potential of managing various resources within the city. The proposed loT system envisions an economical way of analyzing large amounts of information to provide solutions that may be applied in various smart city domains to improve efficiency and service delivery. One of the focuses on the system proposed is efficient solid waste monitoring and collection for smart cities. In order to optimize the entire process of solid waste collection, there will be the implementation of a genetic rule. The genetic rule algorithms will calculate the shortest distance needed to be covered by 
garbage collecting vehicles to reach a particular garbage bin. All the algorithms for the system are integrated into an loT framework that is proposed with the possibility of future modifications.

\section{The Proposed Architecture Of The System}

Figure 1 below illustrates the architecture of the proposed system. The system works entirely on optimization algorithms for the administration of a garbage collection and monitoring framework for smart cities. The proposed system is suitable for any smart city municipality because it can define the shortest routes that can be used by garbage collecting vehicles by reading garbage bins that have exceeded the threshold in terms of level/weight. The garbage bins can be strategically be deployed to any part of the city. Huge garbage bins can be placed in most parts of the city that generate a lot of solid waste like the residential and industrial areas. The total cost incurred during the entire garbage collection process can be divided among individual residents and individual industries, making garbage collection affordable and cheaper to most households and industries. In order to achieve optimal garbage collection, during the first phase, different sensor nodes will be used to collect data from garbage collection points. The garbage containers should not have the same storage capacity because of different locations (which means different amounts of waste generated). Besides, the garbage collection bins should be deployed randomly in the city.

In the second phase, there will be collection of level/weight of each garbage container level/weight, and the data will be fed into a genetic algorithm to find the optimal garbage collection route.

In the third and final phase, the genetic algorithm will execute the input data, and once the genetic algorithm terminates the execution, it will find the optimal route for garbage collection based on the garbage bin filling capacity. Other garbage bin parameters that can be fed into the genetic algorithm include the garbage bin's location coordinates, the garbage bin's capacity, and the current filling ratio of each garbage bin in real-time and the garbage bin's weight in real-time, respectively. Once the genetic algorithm provides the optimal path, the proposed system will have to verify the real-time accuracy and compare it with the existing systems.

\section{Conclusion}

This paper proposes the applicability of loT in solid waste monitoring and collection system for smart cities. The proposed system has demonstrated that solid waste monitoring and management using loT technology empowers people in the public health department to detect when garbage bins have exceeded the threshold in weight/level in real-time. Therefore the system aims to increase the overall cleanliness and productivity. Nonetheless, using wireless sensor nodes to monitor the rate of filling of the garbage bins is highly likely to obtain a more effective and efficient system than the existing systems. The proposed system aims to majorly concentrate on solid waste administration, reducing human interactions with waste, hence cutting down on labor/wages, which means a cleaner and hygienic urban population. 


\section{Declarations}

\section{Data Availability}

Data sharing not applicable to this article as no datasets were generated or analyzed during the current study.

\section{Conflicts of Interest}

The authors declare that they have no conflict of interest.

\section{Author's Contribution}

The research conceptualization and methodology was done by Dominic Abuga. Nallanthighal Raghava was involved in technical review, editing and the final approval of the manuscript.

\section{Acknowledgment}

I will like to thank the Delhi Technological University Library Staff for the support they gave me in accessing the IEEE repository for study materials during this period of Covid-19.

\section{References}

[1] K. Pardini, J. Rodrigues, S. A. Kozlov, N. Kumar, and V. Furtado, "loT-based solid waste management solutions: a survey," Journal of Sensor and Actuator Networks, vol. 8, no. 1, p. 5, 2019.

[2] C. Popa, G. Carutasu, C. Cotet, N. Carutasu, and T. Dobrescu, "Smart city platform development for an automated waste collection system," Sustainability, vol. 9, no. 11, p. 2064, 2017.

[3] Abou Najm, M., El-Fadel, M., 2004. Computer-based interface for an integrated solid waste management optimization model. Environmental Modelling and Software 19, 1151-1164.

[4] C. T ao, and L. Xiang, "Municipal Solid Waste Recycle Management Information Platform Based on Internet of Things Techno logy", IEEE International Conference on Multimedia Information Networking and Security (MINES), 2010, pp. 729 -732.

[5] L. Álvaro, J. Caridad, J. De Paz, G. V. González, and J. Bajo, "Smart waste collection system with low consumption LoRaWAN nodes and route optimization," Sensors, vol. 18, no. 5, pp. 1804-1282, 2018

[6] V. Sanjeevi and P. Shahabudeen, "Optimal routing for efficient municipal solid waste transportation by using ArcGIS application in Chennai, India.," Waste Manag. Res., vol. 34, no. 1, pp. 11-21, 2016.

[7] C. Balakrishna, "Enabling Technologies for Smart City Services and Applications", IEEE 6th International Conference on Next Generation Mobile Applications, Services and Technologies (NGMAST), 2012, pp. 223-227. 
[8] M. Al-Jabi and M. Diab, "loT-enabled citizen attractive waste management system," in Proceedings of the 2017 2nd International Conference on the Applications of Information Technology in Developing Renewable Energy Processes \& Systems (IT-DREPS), IEEE, Amman, Jordan, December 2017.

[9] A. A. J. Jim, R. Kadir, M. A. A. Mamun, A.-A. Nahid, and M. Y. Ali, "A noble proposal for Internet of garbage bins (loGB)," Smart Cities, vol. 2, no. 2, pp. 214-229, 2019.

[10]M. Fazio, M. Paone, A. Puliafito, and M. Villari. "Heterogen eous Sensors Become Homogenous T hings in Smart Cities", IEEE 6th International Conference on Innovative Mobile and Internet Services in Ubiquitous Computing (IMIS), 2012, pp. 775 -780

[11] M. S. Chaudhari, B. Patil, and V. Raut, "lot based waste collection management system for smart cities: an overview," in Proceedings of the 2019 3rd International Conference on Computing Methodologies and Communication (ICCMC), pp. 802-805, IEEE, Erode, India, March 2019.

\section{Figures}

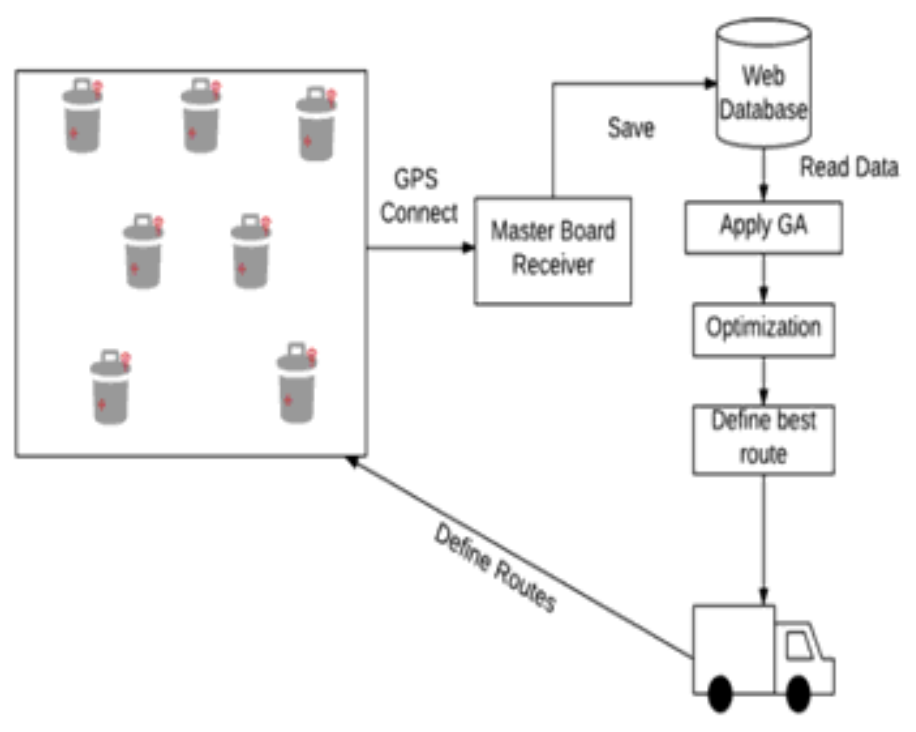

\section{Figure 1}

The proposed Architecture of the system (adapted from [11]) 